\title{
Vom Ertragen der Nichtraucher
}

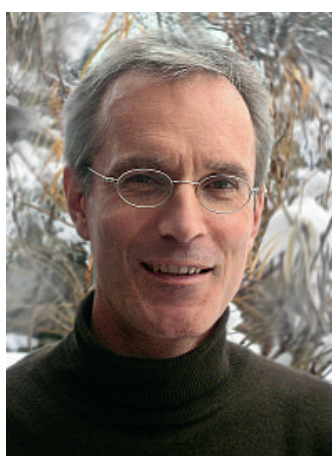

Bruno Kesseli
Eine der erfreulichen Seiten der beschaulichen Zeitspanne zwischen Weihnachten und Neujahr besteht darin, dass man eher als sonst Zeit findet, Freundschaften aus längst vergangenen Tagen zu reanimieren ohne medizinische Hintergedanken, zunächst. Besonders intensiv verspricht das Eintauchen in die eigene Vergangenheit zu werden, wenn es in der ehemaligen Stammkneipe stattfindet, wo man sich mit einem alten Weggefährten zum gemütlichen Essen verabredet hat. Ein atmosphärisch dichtes Erlebnis, in der Tat: Der Eintritt in das Lokal, das man seit den - mehr oder weniger gloriosen - 1980er Jahren nicht mehr von innen gesehen hat, kommt dem Aufprall auf eine rauchgeschwängerte Wand gleich, deren Impact Assoziationen an den gut getimten Haken eines Schwergewichtsboxers weckt. Kurzum: Man ringt nach Luft - und fast wird Reanimation nun auch im medizinischen Sinn zum Thema.

Zugegeben, dieses Stimmungsbild ist etwas dramatisch zugespitzt. Doch die Frage drängt sich dem Besucher auf, wie er die feinstaubgesättigte Mischung des Lokals vor einem Vierteljahrhundert mit schöner Regelmässigkeit zu ertragen imstande war. Und so ergibt sich der thematische Einstieg in den Abend gewissermassen wie von selbst. Denn der Gesprächspartner ist nicht nur Geisteswissenschaftler und Kulturjournalist, sondern auch - und in diesem Kontext vor allem - Raucher. Es entspinnt sich eine lebhafte Diskussion, wie sie in unterschiedlichen Konstellationen schon tausendfach geführt wurde. Wie häufig, wenn die medizinischen Fakten eindeutig und ziemlich unverrückbar auf dem Tisch liegen, verlagert sich die Argumentation auf die philosophische

\section{Der tolerante Raucher erduldet die essenden Mitmenschen am Tisch}

Ebene: Freiheit des Individuums und ihre Grenzen, Eigenverantwortung und Fremdgefährdung, Genuss und Risiko.

Die Geister grosser Denker von Locke über Kant bis Luhmann und wer einem sonst noch grad so in den Sinn kommt, werden beiderseits angerufen und zur Verstärkung der je eigenen Argumentationslinie in die verrauchte Stube herabgezwungen, in der man den Durchblick in verschiedener Hinsicht schon ziemlich verloren hat. Richtig, man ist heute Abend freiwillig in dieses Lokal gekommen (im Gegensatz zu den Angestellten).
Ob des sophistischen Tanzes müde oder um einen versöhnlichen Abschluss bemüht, wird zu guter Letzt noch der Begriff der Toleranz eingeführt. Wenn davon auf beiden Seiten genügend vorhanden wäre, meint der Freund, wären doch alle Probleme zwischen Rauchern und Nichtrauchern so einfach zu lösen. Anstatt nun auch noch Voltaire und Lessing zu bemühen, wird er ganz praktisch-konkret. Seiner Erfahrung nach, verkündet er im Brustton der Überzeugung, seien Raucher im Allgemeinen sehr tolerante Menschen. Für ihn wie für viele andere sei es beispielsweise selbstverständlich, bei Mahlzeiten ihren ersten Glimmstängel erst dann anzuzünden, wenn die gesamte Tafelrunde die Einverleibung der Speisen zu einem befriedigenden Abschluss gebracht habe.

Moment mal. Wie war das? Hat man richtig gehört? Immerhin ist das Gegenüber ein sprachlich durchaus sattelfester Geisteswissenschaftler. Toleranz, so weit ist man sich einig, geht auf tolerare zurück, was bekanntlich so viel wie «erdulden», «ertragen» bedeutet. Der tolerante Raucher erduldet also die essenden Mitmenschen am Tisch, die ihn durch ihr Verhalten (nämlich zu essen) in seinem Wohlbefinden massiv beeinträchtigen? Wie verdienstvoll. Analog dazu verhält sich die werdende Mutter gegenüber ihrem anspruchsvollen Ungeborenen selbstverständlich äusserst tolerant, wenn sie während der Schwangerschaft auf das Rauchen verzichtet. Ganz zu schweigen von der Toleranz der unzähligen arbeitstätigen Raucher, die ihre nichtrauchenden Bürokollegen Tag für Tag klaglos ertragen.

Natürlich können solche Begriffsklärungen eine jahrzehntelange Freundschaft nicht ernstlich trüben - der Kumpel räumt sogar ein, dass der Toleranzbegriff in diesem Zusammenhang wohl nicht ganz angemessen sei. Doch im Grunde genommen sei ja wohl klar, was er gemeint habe. Ist es in der Tat: Der Raucher verzichtet temporär darauf, seiner Leidenschaft zu frönen - er nimmt Rücksicht auf die ihn Umgebenden, von denen er aber seinerseits nichts zu erdulden hat. Was er dagegen wohl oder übel ertragen muss, ist sein eigener Suchtdruck (der zugegebenermassen massiv sein kann) - ein kleiner, aber entscheidender Unterschied.

Wie dem auch sei, denkt man sich beim Verlassen des Lokals, den durch eine beginnende Konjunktivitis leicht beeinträchtigten Blick zwischen den Rauchschwaden hindurch über die zahlreichen essenden Gäste schweifen lassend: Toleranz hin, Rücksichtnahme her - als überzeugend kann man das Endergebnis beim besten Willen nicht bezeichnen.

Bruno Kesseli 